\title{
Infestação do ácaro Varroa destructor em colônias de abelhas africanizadas (Apis mellifera L.) no Semiárido potiguar, Nordeste do Brasil
}

\section{Varroa destructor mite infestation in colonies of Africanized honey bees (Apis mellifera L.) in the potiguar Semi-arid region, Northeastern Brazil}

\author{
Stephano Bismark Lopes Cavalcante Moreira ${ }^{1}$, Guilherme Sampaio Queiroz ${ }^{1}$, Hinkley Alcântara de Castro ${ }^{2}$, Eduardo Alves de \\ Souza ${ }^{3}$, Daniel Santiago Pereira ${ }^{4}$, João Paulo de Holanda Neto ${ }^{5 *}$
}

Resumo: O presente trabalho teve como objetivo analisar os índices de infestação pelo ácaro Varroa. destructor em colônias de abelhas africanizadas (Apis mellifera) de apiários dos municípios de Encanto e de Marcelino Vieira, estado do Rio Grande do Norte. A pesquisa foi conduzida no período de setembro a dezembro de 2014, sendo coletadas em média de 100 a 200 abelhas adultas (nutrizes) retiradas dos quadros centrais do ninho com crias de cada colmeia, aprisionadas em recipientes contendo $100 \mathrm{~mL}$ de álcool a 70\% e encaminhadas para laboratório do Instituto Federal do Rio Grande do Norte (IFRN), para a contagem das abelhas e dos ácaros. Os resultados apresentaram ocorrência do ácaro $V$. destructor em todos apiários e em todas colmeias analisados, obtendo uma infestação média de 7,24\% em Encanto e de 5,25\% em Marcelino Vieira, níveis de infestação baixos $(<15 \%)$, portanto, não acarretando risco às colônias.

Palavras-chave: Apicultura; Semiárido brasileiro; Varroidae; Varroose.

\begin{abstract}
The goal of the present work was to analyze the rates of infestation by Varroa. destructor mite in Africanized honeybees (Apis mellifera) colonies from apiaries in Encanto and Marcelino Vieira cities, state of Rio Grande do Norte. The research was conducted during the period from September to December 2014. In average 100 to 200 adult bees (nursing honey bee workers) were collected from the brood chamber over center frames of with brood of each hive surveyed, trapped in containers containing $100 \mathrm{~mL}$ of $70 \%$ alcohol and sent to the laboratory of the Federal Institute of Rio Grande do Norte (IFRN) for the counting of bees and mites. The results showed an occurrence of the Varroa destructor mite in all apiaries and in all hives analyzed, obtaining an average infestation of $7.24 \%$ in Encanto city and $5.25 \%$ in Marcelino Vieira city, low infestation levels $(<15 \%)$, without risk to the colonies.
\end{abstract}

Key words: Apiculture, Brazilian semiarid; Varroidae; Varroasis.

\footnotetext{
*Autor para correspondência

Recebido para publicação em 10/01/2017; aprovado em: 14/03/2017

${ }^{1}$ Instituto Federal do Rio Grande do Norte, Pau dos Ferros, Rio Grande do Norte, Brasil.

${ }^{2}$ Universidade Federal da Paraíba, Areia, Paraíba, Brasil.

${ }^{3}$ Universidade Federal Rural do Semiárido, Mossoró, Rio Grande do Norte, Brasil.

${ }^{4}$ Empresa Brasileira de Pesquisa Agropecuária, CPATU, Belém, Pará, Brasil. E-mail: daniel.pereira@embrapa.br

${ }^{5}$ Instituto Federal do Sertão Pernambucano, Ouricuri, Pernambuco, Brasil. E-mail: jpholandaneto@gmail.com.
} 


\section{INTRODUÇÃO}

O ácaro Varroa destructor (Varroidae) é um ectoparasita que ataca colônias de abelhas Apis melllifera L., alojando-se geralmente no tórax e abdômen de zangões e operárias para se alimentar de hemolinfa (DE JONG et al.,1982; DI PRISCO et al., 2011), podendo causar sérios danos à saúde das abelhas, principalmente pelo comprometimento da absorção e armazenamento corporal de proteínas, consequentemente afetando ação do sistema imunológico e longevidade, bem como no crescimento e desenvolvimento normal das crias, o que gera indivíduos adultos mal formados e de peso e tamanho reduzidos (AMDAM et al., 2004; GAREDEW et al., 2004; ROSENKRANZ et al., 2010; CAPPELARI, 2011), além da possibilidade de haver a transmissão de forma vertical e horizontal de vírus (SUMPTER; MARTIN, 2004; CHEN et al., 2006; KEVAN, et al., 2006; MATTOS, 2011).

A gravidade da infestação pelo ácaro Varroa pode variar de acordo com as subespécies de abelhas, as condições climáticas, a disponibilidade de alimento no campo, o período de desenvolvimento da ninhada e a capacidade de detectar e remover o parasita das colônias afetadas (MEDINA; MARTIN, 1999; JOHNSON et al., 2009; BAK et al., 2010), uma vez que o ácaro é responsável pela perda de populações de abelhas melíferas, principalmente em regiões de clima temperado (MONDRAGÓN et al., 2005; IBRAHIM e SPIVAK, 2006).

A varroase é apontada, atualmente, como um dos prováveis fatores responsáveis pelo desaparecimento ou colapso de colônias de abelhas (CCD) (MARTIN, 1998; 2001; TORRES; BARRETO, 2013), configurando-se uma preocupação para a manutenção da biodiversidade (POTTS et al., 2010) e a agricultura (WITTER et al., 2014; OLIVEIRA, 2015), visto que as abelhas (BRADBEAR, 2009), principalmente a espécie A. mellifera (CRANE, 1983), representam os principais polinizadores (IMPERATRIZFONSECA; NUNES-SILVA, 2010), responsáveis pela polinização de mais de $70 \%$ das plantas com flores no planeta (KERR, 1999; FAO, 2004; KWAPONG et al., 2010; FREITAS; SILVA, 2015; ALVES, 2015).

Embora o ácaro tenha se tornado uma grande ameaça para colônias de abelhas melíferas pelo mundo, no Brasil, os níveis de infestação em colônias de abelhas africanizadas mostraram-se, historicamente, baixos (inferior a 5\%); não apresentando riscos para a apicultura no país (GONÇALVES, 1986; MATTOS; CHAUD-NETTO, 2011). Contudo, mais recentemente, foram registrados maiores níveis de infestação pelo $V$. destructor, chegando até $11 \%$ no agreste de Pernambuco (CLEMENTINO et al., 2016), de 12\% em Minas Gerais (BACHA-JÚNIOR et al., 2009) e até mesmo de 20,73\% em Mato Grosso (TORRES; BARRETO, 2013).

Carneiro et al (2007) vem alertando que habilidade reprodutiva da fêmea do varroa cresceu nas últimas décadas desde do século passado, dessa forma consequentemente, os índices de infestação tendem a aumentar, porem estes mesmos autores externaram que, os fatores mais determinantes na tolerância da A. mellifera ao acaro em questão estariam no comportamento higiênico, na taxa de mortalidade dos ácaros nas abelhas adultas e bem como na mortalidade dos ácaros nas crias das abelhas.

Entretanto a preocupação com o ácaro varroa vem crescendo cada vez mais, pois mesmo em regiões com baixo índice históricos de infestação de $V$. destrcutor, vírus letais como AKI e DWV podem se espalhar em uma colmeia e entre colmeias, podendo causar sérios danos (FRANCIS et al., 2013).

Recentemente, no Brasil, pelo menos dois tipos de virais transmitidos pela ação de parasita do $V$. destructor foram registrados no Rio Grande do Sul (GARCIA, 2014). Além disso, a presença do ácaro Varroa associado a vírus e ainda acrescentado a deficiência nutricional nas crias e abelhas adultas, principalmente o déficit proteico, reduz severamente a eficiência do sistema imunológico e capacidade de as abelhas resistirem às infecções virais (ALAUX et al., 2010; DEGRANDI-HOFFMAN; CHEN, 2015).

À vista disso, considerando-se a ocorrência do ácaro parasitário ( $V$. destructor) na região do semiárido potiguar (QUEIROZ et al., 2013; 2015; SILVA et al., 2015; MOREIRA et al., 2015), e o baixo nível tecnológico e/ou práticas de manejo inadequadas aplicados nos apiários nordestinos (COSTA-JUNIOR e OLIVEIRA, 2008; SOUZA et al., 2014; HOLANDA-NETO et al., 2015), tornam-se necessários mais estudos para identificar e acompanhar a incidência e o nível de infestação deste parasita na área, na tentativa de, possivelmente, elaborar planos de ação para controle e prevenção de infestação do ácaro Varroa em apiários do Nordeste do Brasil.

Nessa perspectiva, o presente trabalho teve como objetivo analisar os índices de infestação pelo ácaro $V$. destructor em colônias de abelhas africanizadas (A. mellifera) de apiários dos municípios de Encanto e de Marcelino Vieira, na região do Alto Oeste Potiguar, estado do Rio Grande do Norte, Nordeste do Brasil.

\section{MATERIAL E MÉTODOS}

$\mathrm{O}$ estudo foi realizado nos municípios de Encanto $\left(6^{\circ} 6^{\prime}\right.$ $36^{\prime \prime} \mathrm{S}$ e $\left.38^{\circ} 18^{\prime} 24^{\prime \prime} \mathrm{W}\right)$ e de Marcelino Vieira (6 $6^{\circ} 17^{\prime} 38^{\prime \prime} \mathrm{S}$ e $\left.38^{\circ} 10^{\prime} 4^{\prime \prime} \mathrm{W}\right)$, região do Alto Oeste Potiguar, no estado do Rio Grande do Norte. A região apresenta clima semiárido quente e seco (Bsh), com temperatura média histórica de $28^{\circ} \mathrm{C}$, umidade em torno de $66 \%$ e a vegetação é a Caatinga hiperxerófila, caracterizada pela abundância de cactáceas e plantas de porte mais baixo e espalhadas (SILVA; MEDEIROS, 2011; DIAS; SILVA, 2012).

A coleta de dados foi conduzida no período de setembro a dezembro de 2014, utilizando-se 20 colônias de abelhas africanizadas (A. mellifera) instaladas em colmeias padrão Langstroth, distribuídas em cinco apiários para cada um dos municípios, totalizando, portanto, dez apiários avaliados.

Foram coletadas cerca de 100 a 200 abelhas adultas jovens, retiradas dos favos centrais com crias abertas e operculadas do ninho de cada colmeia, e aprisionadas em recipientes contendo $100 \mathrm{ml}$ de álcool a $70 \%$, para em seguida serem encaminhadas para laboratório do Instituto Federal do Rio Grande do Norte (IFRN), campus de Pau dos Ferros, onde estes foram manualmente agitados por um minuto, para que houvesse o despendimento do parasita aderido no corpo da abelha. Em seguida, cada amostra foi depositada em uma bandeja de cor branca, para que pudesse facilmente ser realizada a contagem do número de abelhas e ácaros. A amostragem seguiu metodologia apresentada por Stort et al. (1981), havendo três coletas de dados, com periodicidade quinzenal.

O índice de infestação por varroa foi calculado pelo número de ácaros encontrados dividido pelo número de 
abelhas adultas, multiplicado por 100. Ademais, as médias e os desvios padrão foram calculados para os níveis de infestação totais nos dois municípios.

Os dados de infestação das amostragens entre os municípios foram expressos em valores de média \pm erro padrão bem como mínimos e máximos através do programa estatístico GraphPad Prism versão 5.0. Após análise dos pressupostos paramétrios, diferença estatística entre o índice de infestação (\%) de ácaros varroa dos diferentes municípios estudados (G1 - Marcelino Viera e G2 - Encanto), foram obtidas através do teste $\mathrm{t}$ independente. Todos os dados sofreram transformação do tipo arco seno, entretanto nas tabelas utilizou-se valores não transformados.

\section{RESULTADOS E DISCUSSÃO}

A tabela 1, mostra a análise descritiva comparativa da infestação do varroa entre os dois municípios apresentou diferença significativa $(\mathrm{p}<0,05)$, demonstrando que as colmeias amostradas em Marcelino Vieira apresentaram menor índice de infestação $(5,30 \%)$, contudo ambos os municípios mostram infestação abaixo de $15 \%$, onde segundo Spivak e Reuter (2001) não representaria risco de colapso (ou morte) de abelhas nas colônias, entretanto, esses autores não levaram em consideração a associação vírus e varroa que, de acordo com Martin (2001), essa associação natural pode causar colapso nas colônias da A. mellifera.

Tabela 1. Estatística descritiva comparativa da infestação (\%) das colônias entre os Municípios de Marcelino Viera e de Encanto no Estado do Rio Grande do Norte. Nordeste do Brasil

\begin{tabular}{ccccc}
\hline Localidades & Média & $\begin{array}{c}\text { Erro } \\
\text { padrão }\end{array}$ & $\begin{array}{c}\text { Mínimo - } \\
\text { Máximo }\end{array}$ & p-valor \\
\hline G1 & 5,30 & 0,76 & $2,10-10,39$ & $0,027^{*}$ \\
G2 & 7,76 & 0,69 & $4,44-10,43$ & \\
\hline
\end{tabular}

* Diferença estatística (p<0,05); G1 = Marcelino Vieira; G2 = Encanto.

Esses índices médios de infestação registrados nas colônias foram relativamente baixos, corroborando com outros resultados observados em diferentes estados do Brasil, como em Santa Catarina (6,2\%) (SCHAFASCHEK et al., 2016), Paraná (8,3\%) (WIELEWSKI et al., 2012), São Paulo $(5,41 \%)$ (SANTOS et al., 2014) e no estado da Paraíba $(6,46 \%)$ (OLINTO, 2014), o qual possui condições edafoclimáticas semelhantes ao semiárido do Alto Oeste Potiguar.

Em Marcelino Vieira, foram observadas as menores taxas de infestação (Figura 1), ratificando os baixos índices já registrados no município em estudo anterior (inferiores a 5\%) (MOREIRA et al., 2015) e próximos aos resultados observados em municípios dos estados da Bahia e de Sergipe, com níveis inferiores a 4\% (BRITO, 2014). Os baixos níveis de infestação pelo ácaro em Marcelino Vieira podem ser atribuídos ao nível tecnológico do manejo apícola empregado e/ou no maior cuidado na escolha dos apiários pelos apicultores com melhores condições para apicultura (SOUZA et al., 2014), onde, por exemplo, a simples renovação de cera dos favos da colmeia pode promover a redução a infestação do ácaro (V. destructor) (PICCIRILLO e DE JONG, 2004).

Ao comparar ambos os municípios, percebe-se que Encanto apresentou um maior nível de infestação nas colônias $(7,24 \%)$ (Tabela 1), valor diferente dos que já foram observados em estudos anteriores no município, como de $1,08 \%$ durante o período chuvoso e de $18,9 \%$ no período seco (QUEIROZ et al., 2013; 2015), o que explica a proporcionalidade entre o crescimento do número de ácaros nas colônias nos indivíduos adultos e as condições desfavoráveis de clima para manutenção das crias (SANTOS et al., 2014), uma vez que a pouca disponibilidade de alimento para as abelhas adultas no campo tem efeito direto na redução da área de cria e significativo aumento de $V$. destructor na colônia em abelhas adultas, pois estas não tem como continuar o ciclo normal de vida por falta de alvéolos com larvas na idade certa, dessa forma permanecendo por mais tempo no corpo das abelhas adultas se alimentando da hemolinfa (JUNKES et al., 2007).

Observou-se que nos três monitoramentos de ambos os municípios foram registradas taxas médias de infestação abaixo de $10 \%$ (Tabela 2), demonstrando que esses níveis estáveis de infestação (CARNEIRO et al., 2014; SANTOS et al., 2015), possivelmente pode-se atribuir ao desenvolvimento de mecanismos de resistência pela abelha africanizada ( $A$. mellifera) (MORETTO et al., 1991), tendo em conta que essas abelhas possuem maior eficiência no comportamento de remoção de ninhadas infestadas pelo $V$. destructor em relação às abelhas europeias (GUERRA-JÚNIOR et al., 2000).

Muito embora os resultados médios obtidos estejam abaixo do nível preocupante de infestação, tiveram ainda registros de níveis mais elevados, principalmente no município do Encanto onde algumas amostras ultrapassaram a $10 \%$, e chegando até $21,12 \%$ em única colmeia no município Marcelino Vieira (Tabela 2). Portanto, mesmo em regiões de clima tropical, é fundamental realizar o acompanhamento das taxas de incidência de $V$. destructor (MATTOS e CHAUDNETTO, 2011), haja vista que somente com a sua presença em altos índices de infestação pode implicar na redução do crescimento, desenvolvimento e produtividade das colônias (A. mellifera) (FRIES et al., 2003).

Os resultados deste estudo evidenciam que a presença do ácaro V. destructor (Figura 1) nos municípios de Encanto e Marcelino Vieira e que a infestação pode ser considerada como baixa, não significando risco às abelhas, bem como não prejudicando as atividades das colônias (A. mellifera) (SILVA, 2010). Destacamos ainda que as colônias utilizadas nesse levantamento não foram observados comportamento de abandono ou mortalidade das abelhas (A. mellifera) em decorrência da infestação pelo ácaro.

Figura 1. Valores de média \pm erro padrão (\%) da infestação do varroa nas localidades dos municípios de Marcelino Vieira (G1) e de Encanto (G2).

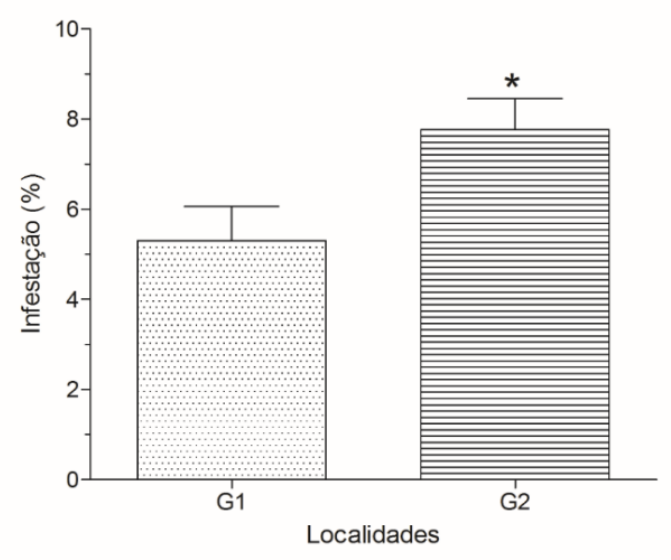


Tabela 2. Taxa de infestação (\%) pelo ácaro Varroa destructor em colônias de abelhas africanizadas (Apis mellifera L.) nos três períodos de coleta, em dois municípios do semiárido potiguar, Rio Grande do Norte, Nordeste do Brasil

\begin{tabular}{|c|c|c|c|c|}
\hline \multirow{2}{*}{ Município } & \multirow{2}{*}{ Colônia } & \multicolumn{3}{|c|}{ Taxa de infestação (\%) } \\
\hline & & Coleta 1 & Coleta 2 & Coleta 3 \\
\hline \multirow{11}{*}{ Encanto } & 01 & 4,59 & 7,87 & 10 \\
\hline & 02 & 5,24 & 15,67 & 8,74 \\
\hline & 03 & 5,81 & 10,88 & 8,93 \\
\hline & 04 & 4,87 & 11,94 & 10,83 \\
\hline & 05 & 4,05 & 11,94 & 15,32 \\
\hline & 06 & 4,98 & 10,19 & 6 \\
\hline & 07 & 7,84 & 10,53 & 11,57 \\
\hline & 08 & 3,59 & 12,04 & 0,71 \\
\hline & 09 & 3 & 4,49 & 5,83 \\
\hline & 10 & 8,17 & 3,03 & 4,35 \\
\hline & Médias & $5,21 \pm 1,68$ & $9,86 \pm 3,77$ & $8,23 \pm 4,14$ \\
\hline \multirow{11}{*}{ Marcelino Vieira } & 11 & 7,83 & 1,5 & 3,03 \\
\hline & 12 & 4,14 & 2,19 & 0 \\
\hline & 13 & 9,09 & 0,98 & 1,91 \\
\hline & 14 & 8,33 & 5 & 7,84 \\
\hline & 15 & 7,89 & 1,67 & 2,46 \\
\hline & 16 & 21,13 & 8,04 & 2,01 \\
\hline & 17 & 5,5 & 5,13 & 5,38 \\
\hline & 18 & 12,18 & 7,22 & 3,33 \\
\hline & 19 & 4 & 3,85 & 3,33 \\
\hline & 20 & 5,5 & 5 & 3,53 \\
\hline & Médias & $8,56 \pm 5,07$ & $4,68 \pm 2,1$ & $3,28 \pm 2,11$ \\
\hline
\end{tabular}

Figura 2. Vistas dorsal (A) e ventral (B) de ácaro Varroa destructor identificado em colônias de abelhas africanizadas (Apis mellifera L.) em dois municípios do semiárido potiguar, Rio Grande do Norte, Nordeste do Brasil

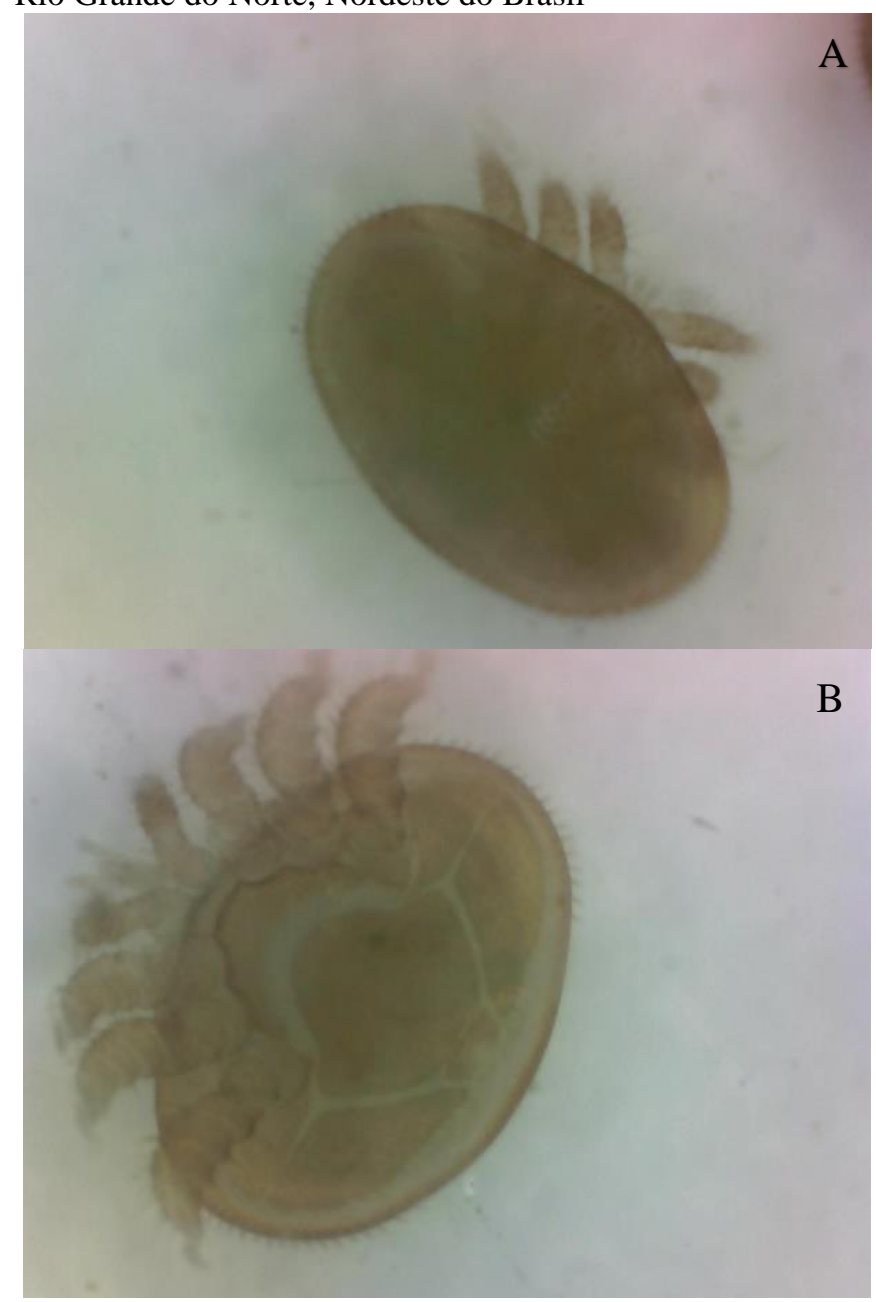

\section{CONCLUSÕES}

A presença do ácaro $V$. destructor nas colônias com abelhas A. mellifera foi considerada baixa, porém todas as colmeias amostradas apresentaram a presença do $V$. destructor.

Os índices infestação em abelhas adultas são notoriamente destacados serem influenciados por diversos fatores (comportamento higiênico, raças de Apis mellifera, habilidade reprodutiva e taxa de mortalidade do varroa), bem como possivelmente nos fatores climáticos e ambientais específicos de cada região, que diretamente influenciam no nível da oferta dos recursos naturais.

A identificação dos níveis de infestação do ácaro ( $V$. destructor) deve ser uma ação de monitoramento constante, pois a associação entre vírus e o varroa, no Brasil, é real e o risco da dispersão e transmissão de vírus pelo acarro na região do Semiárido nordestino.

\section{REFERÊNCIAS}

ALAUX, C.; DUCLOZ, F.; CRAUSER, D.; COUNTE, Y. L. Diet efects on honeybee immunocompetence. Biology Letters, v. 17, p. 01-04, 2010.

AMDAM, G. V.; HARTFELDER, K.; NORBERG, K.; HAGEN, A.; OMHOLT, S. W. Altered physiology in worker honey bees (Hymenoptera: Apidae) infested with the mite Varroa destructor (Acari: Varroidae): a factor in colony loss during overwintering? Journal of Economic Entomology, v. 97, n. 3, p. 741-747, 2004.

ALVES, D. A. A importância da paisagem agrícola no serviço de polinização das abelhas. In: ABELHA. Associação Brasileira de Estudos das Abelhas. Agricultura e polinizadores. São Paulo: ABELHA, 2015. p. 32-43. 
BACHA-JÚNIOR, G. L.; FELIPE-SILVA, A. S.; PEREIRA, P. L. L. Taxa de infestação por ácaro Varroa destructor em apiários sob georreferenciamento. Arquivo Brasileira de Medicina Veterinária e Zootecnia, v. 61, n. 6, p. 1471-1473, 2009.

BAK, B.; WILDE, J., SIUDA, M. Comparison of hygienic behaviour between five honey bee breeding lines. Journal of Apicultural Science, v. 54, n. 2, p. 17 -24. 2010.

BRADBEAR, N. The importance of bees in nature. In: BRADBEAR, N. Bees and their role in forest livelihoods: a guide to the services provided by bees and the sustainable harvesting, processing and marketing of their products. Roma: FAO/ONU, 2009. p. 13-16

BRITO, R. L. Sistema de Informação Geográfica aplicado ao diagnóstico do ácaro Varroa destructor em apiários na região nordeste do Brasil. 2014. 63 f. Dissertação (Mestrado em Ciência Animal nos Trópicos) - Universidade Federal da Bahia, Salvador. 2014

CAPPELARI, F. A. Efeito do tamanho da célula do favo e da infestação do ácaro Varroa destructor sobre a morfometria da asa e da longevidade da sua hóspede, abelha Apis mellifera. 2011. 137 f. Tese (Doutorado) - Universidade de São Paulo, Ribeirão Preto. 2011.

CARNEIRO, F.E.; TORRES, R. R.; STRPAZZON, R.; RAMÍREZ, S. A.; GUERRA JR, J. C. V.; KOLING, D. F.; MORETTO, G. Changes in the reproductive ability of the mite Varroa destructor (Anderson e Trueman) in africanized honey bees (Apis mellifera L.) (Hymenoptera: Apidade) colonies in Southern Brazil. Neotropical Entomology, v.36, n. 6, p, 949-952, 2007.

CARNEIRO, F. E.; BARROSO, G. V.; STRAPAZZON, R.; MORETTO, G. Reproductive ability and level of infestation of the Varroa destructor mite in Apis mellifera apiaries in Blumenau, State of Santa Catarina, Brazil. Acta Scientiarum. Biological Sciences, v. 36, n. 1, p. 109-112, 2014.

CHEN, Y.; EVANS, J,; FELDLAUFER, M. Horizontal and vertical transmission of viroses in the honey bee. Apis mellifera. Journal of Invertebrate Pathology, v. 92 p. 152-159, 2006.

CLEMENTINO, D. C.; GALINDO, G. M.; MILFONT, M. O. Taxa de infestação da Varroa destructor em colônias de Apis mellifera L. no Agreste Meridional de Pernambuco. Revista Verde de Agroecologia e Desenvolvimento Sustentável, v. 11, n. 3, p. 177-181, 2016.

COSTA-JÚNIOR, M. P.; OLIVEIRA, M. A. S. Nível tecnológico da produção de mel de abelha no estado Ceará: análise comparativa do Pólo de Santana do Cariri com os Pólos de Mombaça e Pacajus/Chorozinho. In: CONGRESSO DA SOCIEDADE DE ECONOMIA, ADMINISTRAÇÃO E SOCIOLOGIA RURAL, 46., 2008. Rio Branco. Anais. Brasília: SOBER, 2008. p.1-20.

CRANE, E. O livro do mel. São Paulo: Nobel, 1983. 226 p.
DEGRANDI-HOFFMAN, G.; CHEN, Y. Nutrition, immunity and viral infections honey bees. Current Opinion in Insect Science. v. 10, p. 170-176, 2015.

DE JONG, D.; MORSE, R. A.; EICKWORT, G. C. Mite pests of honeybees. Annual Review of Entomology, v.27, p. 229-252, 1982

DI PRISCO, G.; PENNACCHIO, F.; CAPRIO, E.; BONCRISTIANI, H. F.; EVANS, J. D.; CHEN, Y. Varroa destructor is an effective vector of Israeli acute paralysis virus in the honeybee, Apis mellifera. Journal of General Virology, v. 92, p. 151-155, 2011.

DIAS, A. S.; SILVA, C. N. M. O processo de formação e expansão do bairro Edilton Fernandes - Marcelino VieiraRN. Revista Geotemas, v. 2, n. 2, p. 1-16, 2012.

FAO. Food and Agriculture Organization of the United Nations. Conservation and management of pollinations for sustainable agriculture. In: FREITAS, B. M.; PEREIRA, J. O. Solitary bees: conservation, rearing and management for pollination. Fortaleza/CE: Imprensa Universitária, 2004. p. 19-25.

FRANCIS, R. M.; NIELSEN, S. L.; KRYGER, P. Varroavirus interaction in collapsing honey bee colonies. Plos One, v. 8, n. 3, p. 01-09, 2013

FREITAS, B. M.; SILVA, C. I. O papel dos polinizadores na produção agrícola no Brasil. In: ABELHA. Associação Brasileira de Estudos das Abelhas. Agricultura e polinizadores. São Paulo: ABELHA, 2015. p. 9-18.

FRIES, I.; HANSEN, H.; IMDORF, A.; ROSENKRANZ, P. Swarming in honeybees (Apis mellifera) and Varroa destructor population development in Sweden. Apidologie, v. 34 , p. 389-397, 2003.

GARCIA, F. W. Identificação de virus que afetam Apis mellifera associados ao ácaro ectoparasita Varroa destructor em apiários do Rio Grande do Sul. 80 f. 2014. Dissertação (Mestrado) - Universidade Federal do Pampa. 2014.

GAREDEW, A.; SCHOMOLZ, E.; LAMPRECHT, I. The energy and nutritional demand of the parasitic life of the mite Varroa destructor. Apidologie, v. 35 p. 419-430, 2004.

GUERRA-JÚNIOR, J. C.; GONÇALVES, L. S.; DE JONG, D. Africanized honey bees (Apis mellifera L.) are more efficient at removing worker brood artificially infested with the parasitic mite Varroa jacobsoni Oudemans than are Italian bees or Italian/Africanized hybrids. Genetics and Molecular Biology, v, 23, n. 1, p. 89-92, 2000.

GONÇALVES, L. S. The Varroa research program in the honeybee laboratory of the University of São Paulo in Ribeirão Preto. Apidologie, v. 17, p. 371-374, 1986.

HOLANDA-NETO, J. P.; PAIVA, C. S.; MELO, S. B.; PAIVA, A. C. C.; MARACAJÁ, P. B.; SILVA, A. F.; PEREIRA, D. S. Comportamento de abandono de abelhas 
africanizadas em apiários durante a entressafra, na região do Alto Oeste Potiguas, Brasil. Agropecuária Científica no Semiárido, v. 11, n. 2, p. 77-85, 2015.

IBRAHIM, A.; SPIVAK, M. The relationship between hygienic behavior and suppression of mite reproduction as honey bee (Apis mellifera) mechanisms of resistance to Varroa destructor. Apidologie, v. 37, p. 32-40, 2006.

IMPERATRIZ-FONSECA, V. L.; NUNES-SILVA, P. As abelhas, os serviços ecossistêmicos e o Código Florestal Brasileiro. Biota Neotropica, v. 10, n. 4, 2010.

JOHNSON, R. M.; POLLOCK, H. S.; BEREBAUM, M. R. Synergistic interactions between in-hive miticides in Apis mellifera. Journal of Economic Entomology, v. 102, n. 2, p. 474-479, 2009.

JUNKES, L.; GUERRA-JÚNIOR, J. C.; MORETTO, G. Varroa destructor mite mortality rate according to the amount of worker broods in africanized honey bee (Apis mellifera L.) colonies. Acta Scientiarum. Biological Scienses, v. 29, n. 3, p. 305-308, 2007.

KEVAN, P. G.; HANNAN, M. A.; OSTIGUY, N.; GUZMAN-NOVOA, E. A summary of the Varroa-virus diseases complex in honey bees. Americam Bee Journal, v. 146, n. 8, p, 694-697, 2006.

KERR, W. E. A importância da meliponicultura para o país. Biotecnologia, Ciência \& Desenvolvimento, v. 1, p 42-44, 1997.

KWAPONG, P.; AIDOO, K.; COMBEY, R.; KARIKARI, A. Stingless bees: importance, management and utilization. Accra: Unimax MacMillan, 2010. 72 p.

MARTIN, S. A population model for the ectoparasitic mite Varroa jacobsoni in honey bee (Apis mellifera) colonies. Ecological Modelling, v. 109, p. 267-281, 1998.

MARTIN, S. J. The role of varroa and viral pathogens in the collapse of honeybee colonies: a modelling approach. Journal of Aplied Ecology, v. 38, p. 1082-1093, 2001.

MATTOS, I. M.; CHAUD-NETTO, J. Effects of Natural Infestations of the Mite Varroa destructor on the Development of Africanized Honeybee Workers (Apis mellifera). Sociobiology, v. 58, n. 1, p. 85-93, 2011.

MATTOS, I. M. Efeito da infestação do ácaro Varroa destructor (Anderson e Treuman, 2000) (Arachnida: Acari: Varroidae) no desenvolvimento de abelhas africanizadas Apis mellifera (Linnaeus, 1758) (Hymenoptera: Apidae). 2011. 63 f. Dissertação (Mestrado em Ciências Biológicas) Universidade Estadual Paulista "Júlio de Mesquita Filho", Rio Claro. 2011.

MEDINA, L. M.; MARTIN, S. J. A comparative study of Varroa jacobsoni reproduction in worker cells of honey bees (Apis mellifera) in England and Africanized bees in Yucatan, Mexico. Experimental and Applied Acarology, v. 23, p. 659667, 1999.
MONDRAGÓN, L; SPIVAK, M. VANDAME, R. A multifactorial study of the resistance of honeybees Apis mellifera to the mite Varroa destructor over one year in Mexico. Apidologie, v. 26, p. 345-358, 2005.

MORETTO, G.; GONÇALVES, L. S.; DE JONG, D.; BICHUETTE, M. Z. The effects of climate and bee race on Varroa jacobsoni Oud infestations in Brazil. Apidologie, v. 22, p. 197-203, 1991.

MOREIRA, S. B. L. C.; QUEIROZ, G. S.; HOLANDANETO, J. P.; PEREIRA, D. S. Avaliação da taxa de infestação pelo ácaro Varroa destructor em abelhas operarias de Apis mellifera (hymenoptera: apidae) em um apiário no município de Marcelino Vieira, RN. In: SEMINÁRIO BRASILEIRO DE PRÓPOLIS E PÓLEN, 2., 2015. Ilhéus. Anais. Ilhéus: CEPLAC, 2015.

OLINTO, F. A. Comportamento higiênico e identificação de patógenos em colmeias de Apis mellifera L. africanizadas no sertão paraibano. 2014. 60 f. Dissertação (Mestrado em Sistemas Agroindustriais) - Universidade Federal de Campina Grande, Pombal. 2014.

OLIVEIRA, M. O. Declínio populacional das abelhas polinizadoras de culturas agrícolas. Acta Apicola Brasilica, v. 3, n. 1, p. 01-06, 2015.

PICCIRILLO, G. A.; DE JONG, D. Old honeybee brood combs are more infested by the mite

Varroa destructor than are new brood combs. Apidologie, v. 35, p. 359-364, 2004.

POTTS, S.; BIESMEIJER, J.; NEUMANN, P.; SCHWEIGER, O.; KUNIN, W. Global pollinator declines: trends, impacts and drivers. Trends in Ecology e Evolution, v. 25 , n. 6 , p. $345-353,2010$.

QUEIROZ, G. S.; LEITE, I. T.; BRITO, L. N.; GODEIRO, R. L. C.; MESQUITA, L. X.; BATISTA, J. S.; PEREIRA, D. S. Avaliação da população de ácaros Varroa destructor em abelhas africanizadas adultas no Encanto-RN. In: SEMINÁRIO BRASILEIRO DE PRÓPOLIS E PÓLEN, 2., 2013. Ilhéus. Anais. Cruz das Almas: Magistra, 2013.

QUEIROZ, G. S.; MOREIRA, S. B. L. C. M.; PAIVA, C. S.; PEREIRA, D. S.; HOLANDA-NETO, J. P. Avaliação do índice de infestação de ácaro Varroa destructor em apiário no município de Encanto, Rio Grande do Norte. In: SEMINÁRIO BRASILEIRO DE PRÓPOLIS E PÓLEN, 2., 2015. Ilhéus. Anais. Ilhéus: CEPLAC, 2015.

ROSENKRANZ, P.; AUMEIER, P.; ZIEGELMANN, B. Biology and control of Varroa destructor. Journal of Invertebrate Pathology, v. 103, p. 96-119, 2010.

SANTOS, L. G.; ALVES, M. L. T. M. F.; MESSAGE, D.; PINTO, F. A.; SILVA, M. V. G. B.; TEIXEIRA, E. W. Honey bee health in apiaries in the Vale do Paraíba, São Paulo State, Southeastern Brazil. Sociobiology, v. 61, n. 3, p. 307-312, 2014. 
SANTOS, P. R.; WIELEWSKI, P.; HALAK, A. L.; FAQUINELLO, P.; TOLEDO, V. A. A. Varroa destructor mite in Africanized honeybee colonies Apis mellifera L. under royal jelly or honey production. Acta Scientiarum. Animal Sciences, v. 37, n. 3, p. 315-322, 2015.

SCHAFASCHEK, T. P.; HICKEL, E. R.; PEREIRA, H. L.; OLIVEIRA, C. A. L.; TOLEDO, V. A. A. Performance of Africanized honeybee colonies settled by queens selected for different traits. Acta Scientiarum. Animal Sciences, v. 38, n. 1, p. 91-100, 2016.

SILVA, F. E. J.; SOUZA, E. A.; SILVA, M. R.; MEDEIROS, V. F.; SILVEIRA-NETO, A. A. Índice de infestação do ácaro Varroa destructor, em colônias de abelhas Apis mellifera no município de Marcelino Vieira-RN. In: REUNIÃO ANUAL DA SOCIEDADE BRASILEIRA PARA O PROGRESSO DA CIÊNCIA, 67., 2015. São Carlos. Anais. São Paulo: SBPC, 2015.

SILVA, A. P. M.; MEDEIROS, J. F. Problemas socioambientais causados pelas indústrias de cerâmicas no município de Encanto-RN. Revista Geotemas, v. 1, n. 1, p. 67-77, 2011.

SILVA, C. M. R. Luta contra Varroa destructor Anderson \& trueman: avaliação de estratégias biotécnicas e bioquímicas com o óleo de Mentha cervina L. 2010. 90 f. Dissertação (Mestrado em Engenharia Florestal e dos Recursos Naturais) - Universidade Técnica de Lisboa, Lisboa. 2010.

SOUZA, E. A.; VAZ, R. S.; SILVA, F. E. J.; PEREIRA, D. S.; HOLANDA-NETO, J. P. Nível tecnológico empregado no manejo para produção de mel de Apis mellifera L. em três municípios do Alto Oeste Potiguar. Acta Apicola Brasilica, v. 2, n. 1, p. 16-23, jan./dez. 2014.

STORT, A. C.; GONÇALVES, L. S.; MALASPINA, O.; MOURA-DUARTE, F. A. Studyons on sineacar effectiveness in controlling Varroa jacobsoni. Apidologie, v. 12, p. 289297, 1981.

SPIVAK, M.; REUTER, G. Varroa destructor infestation in untreated honeybee (Hymenoptera: Apidae) colonies selected for hygienic behavior. Journal of Economic Entomology, v. 94, n. 2, p. 327-331, 2001.

SUMPTER, D. J. T.; MARTINI, S. J. The dynamics of virus epidemics in Varroa-infested honey bee colonies. Journal of Animal Ecology, v. 73, p. 51-63, 2004.

TORRES, R. N. S.; BARRETO, M. R. Incidência de Varroa destructor (Anderson \& Trueman) em criação de abelhas com ferrão na região de Sinop, Mato Grosso, Brasil. EntomoBrasilis, v. 6, n. 1, p. 30-33, 2013.

WIELEWSKI, P.; TOLEDO, V. A. A.; MARTINS, E. N.; COSTA-MAIA, F. M.; FAQUINELLO, P.; LINOLOURENÇO, D. A.; RUVOLO-TAKASUSUKI, M. C. C.; OLIVEIRA, C. A. L.; SEREIRA, M. J. Relationship between hygienic behavior and Varroa destructor mites in colonies producing honey or royal jelly. Sociobiology, v. 59, n. 1, 2012.

WITTER, S.; NUNES-SILVA， P.; BLOCHTEIN， B.; LISBOA, B. B.; IMPERATRIZ-FONSECA, V. L. As abelhas e a agricultura. Porto Alegre: EDIPUCRS, 2014. 143 p.. 